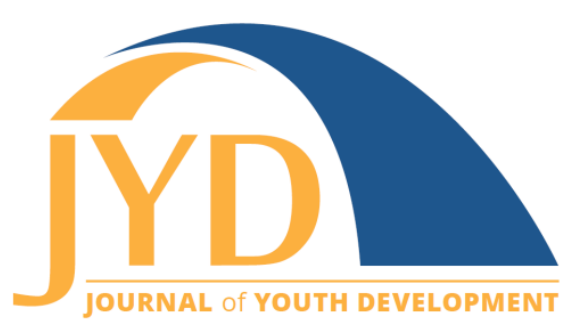

http://jyd.pitt.edu/ | Vol. 15 Issue 4 DOI 10.5195/jyd.2020.857 | ISSN 2325-4017 (online)

\title{
Evaluating a Statewide 4-H Volunteer Structure for Protection and Ease
}

\author{
Jamie Morris \\ University of Maryland Extension, 4-H Youth Development \\ jkenton@umd.edu \\ Lacie Ashby \\ University of Maryland Extension, 4-H Youth Development \\ lashby@umd.edu
}

\begin{abstract}
Organizations that engage volunteers to enhance and extend programs in order to meet their mission and goals often have a process to onboard individuals to serve. These processes are typically designed to provide protection to the volunteer and the organization; however, they are only as strong as the policies and procedures set in place. This article overviews one state's process to review and revise their 4-H program's volunteer structure to improve the consistency and cohesion of its use and the protection for all involved.
\end{abstract}

Key words: volunteer engagement, volunteer management, volunteer system, strategic review, risk management

\section{Introduction}

Volunteers are essential to 4-H programs across the United States and are recognized as cornerstones of its conceptualization. "The practice of having volunteers lead 4-H clubs was established at the beginning and continues today" (Vanhorn et al., 1998, para. 7). Although there are differences from state to state, the impact volunteers have on youth and the 4-H program is tremendous. Approximately 500,000 volunteers engage with over six million youth on behalf of the 4-H program nationally. Volunteers spend thousands of hours of their "free

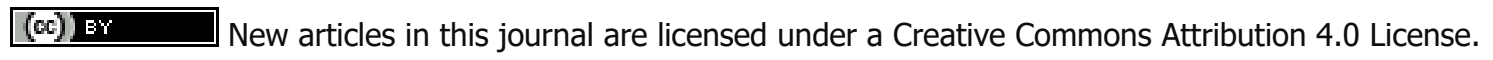
This journal is published by the University Library System, University of Pittsburgh and is cosponsored by the University of Pittsburgh Press. The Journal of Youth Development is the official peer-reviewed publication of the National Association of Extension 4-H Youth Development Professionals and the National AfterSchool Association. 


\section{Evaluating a Statewide 4-H Volunteer Structure}

time" serving as club and/or project leaders, camp staff, mentors and a variety of other roles to help create a safe and inclusive environment for youth to learn, grow, and thrive.

Organized under the Cooperative Extension system, 4-H programs know the tremendous impact volunteers have on youth and on $4-\mathrm{H}$ program success overall. This should be reason enough to motivate State Cooperative Extension systems to create a consistent, cohesive volunteer delivery system or "unified, orderly process for coordinating and overseeing the work of volunteers and their partnership with staff at all levels of the county program" (Plesak, 2010, p. 1).

Ultimately volunteers are trained, prepared, and engaged to meet the needs of the program and/or organization. "Volunteers frequently have a high public visibility on behalf of a nonprofit corporation; they are the persons whom individuals dealing with the nonprofit corporation see first and most often" (DeWitt, 1995, as cited in Schmiesing \& Henderson, "Introduction," para. 1). The fact that they work with youth on behalf of 4- $\mathrm{H}$, Extension and the Land Grant University System is another reason to have a strong volunteer system that provides expectations of how to become a volunteer and how to serve and represent safely and appropriately.

There is frequent recommendation in the literature about the importance of using best practices in orientation and training to improve 4-H program quality. However, in today's litigious society there are other grounding pieces that should be present to ensure the protection of the 4-H program and the volunteers donating their time. Applying sound management practices and keeping the rights and responsibilities of volunteers in mind are foundational practices to foster an effective volunteer management program (Seevers et al., 1997). Important legal considerations include volunteer screening, required and ongoing training, and proper documentation which provide for the safety, health, and integrity of the program.

Most 4-H volunteers serve under the supervision of an Extension employee tasked with the duties of volunteer engagement, historically referred to as volunteer management. Regardless of their title, Extension professionals provide the leadership and guidance to the volunteer delivery system for their assigned program or region, supporting volunteers at the "grassroots" level. The volunteer system is typically overseen at the state or administration level which includes the structure and security through the development and implementation of policies, 


\section{Evaluating a Statewide 4-H Volunteer Structure}

procedures, and processes that all are expected to follow in order to best protect the youth, volunteers, and organization.

\section{Background and Reasoning for Statewide Review}

Like many organizations, the University of Maryland Extension (UME), in 1997, followed the trends in volunteerism, dedicating intentional effort toward the creation of a concise volunteer system with policies, procedures and supporting documents. This system provided the basic requirements and practices to allow individuals to serve as volunteers for any of the Extension programs: 4-H Youth Development, Agriculture, Environment and Natural Resources, and Family and Consumer Sciences. Foundational documents and processes including the UME Volunteer Policies and Procedures were created, which provided expectations and requirements to screen, select, appoint, and manage volunteers. These processes and documents evolved over the years with periodic revisions; however, current versions were last revised in 2013 creating concerns in application as well as in the understanding and adherence to the policies, procedures, and documentation.

In December 2016, after a review of the volunteer process with University legal counsel, the UME 4-H Program was advised to discontinue the use of the short-term volunteer role, which was included in the UME Volunteer Policies and Procedures. A short-term volunteer was one that was to have limited interactions with program participants and serve in a non-permanent role. Such individuals served under the supervision of an employee or volunteer but were not considered representatives of UME. The UME Volunteer Policies and Procedures did not provide implementation or utilization guidelines, nor did it require short-term volunteers to be screened and trained as was expected of Certified UME Volunteers. These inconsistencies in the policy led to conflicting uses of this role across the state, sometimes being used in place of the volunteer certification process because it required less paperwork.

Legal counsel found that the use of the short-term volunteer role, especially for 4- $\mathrm{H}$ programming, posed a higher risk and greater liability to the organization due to two major shortfalls:

1. The absence of any required screening or vetting process Short-term volunteers did not have to apply for their position, were not reference- or background-checked, and did not have to submit to an interview or orientation. Certified volunteers, on the other hand, are required to apply; submit to a reference- and 


\section{Evaluating a Statewide 4-H Volunteer Structure}

background-check; and participate in an interview and orientation process, after which, if they pass, they can be appointed to a Certified UME 4-H volunteer role.

2. The lack of substantial documentation

Short-term volunteer documentation was a one-page appointment agreement that legal counsel deemed did not include the necessary components and verbiage to provide adequate protection for the individual volunteering, under the Maryland Torts Claim Act. In contrast, appointed certified volunteers sign a volunteer appointment agreement, a position description for each role they are assigned, and an Adult Code of Conduct.

The insubstantial documentation for the short-term volunteer role in particular left the organization open to legal implications, despite the appointment document giving the appearance of protection. Therefore, based on legal counsel's advice, the UME 4-H Program decided to manage and mitigate their legal risk through a strategic management approach and review of the volunteer system. Seevers and colleagues (1997) found that an awareness of volunteer rights and responsibilities could provide a foundation for an effective volunteer management system and help organizations avoid the pitfalls associated with poor volunteer management. It is imperative to find a balance between the need to utilize volunteers to meet program goals and the need to manage and/or mitigate risk to avoid potential legal concerns in order to provide as much support and protection as possible to volunteers serving on behalf of any program or organization.

\section{Strategic Management}

Based on UME legal advice to mitigate risk to the organization, all 4-H faculty and staff were notified early in 2017 to discontinue using the short-term volunteer role and form. Although supported by 4-H and UME administration, this discontinuation posed a potential problem to field faculty and operations of 4-H programs that used the short-term volunteer role, mainly for individuals serving in a limited capacity at fairs or single-day events. In alignment with effective risk management practices, including steps such as adopting and following written policies and procedures, ensuring that staff and board members understand and perform their duties, screening and evaluating volunteers and employees, insulating the organization against lawsuits, and being prepared for worst-case scenarios (Tremper \& Kostin, 1993), the State 4-H Program tasked an internal working committee to review and provide suggestions to address these concerns. The Maryland 4-H Development of the Practitioner focus group (practitioner group) led by the state volunteer specialist and two field faculty members, utilized strategic 


\section{Evaluating a Statewide 4-H Volunteer Structure}

management to complete their assignment. "Strategic management is defined as those approaches, used by persons responsible for volunteer program implementation to enhance capacity, sustain programs, and collaborate with others to move toward change while simultaneously never losing sight of their core organizational and programmatic values" (Seel, 2010, p. 83). The practitioner group set out a plan to review all documents, resources and concerns with the short-term volunteer role in order to discuss and address needed changes and develop an implementation plan to fill the void created by the absence of the short-term volunteer role with the intention of providing structure for the future and creating a scaffold to transition from the past. The strategic management methods described herein are used widely in private-sector organizations to accomplish their objectives but are rarely used in the not-forprofit environment (Montanari \& Bracker, 1986). Therefore, it is the authors' hope that the process used to systematically review, revise, and reinforce the UME volunteer structure may be applied to other organizations in similar situations who rely on volunteers as heavily as $4-\mathrm{H}$.

\section{The UME 4-H Review Process}

The strategic review process utilized by UME 4-H included the following steps:

\section{Analysis}

- situation review

- resource review (documents, policies, and processes)

- resource evaluation (discussion of utilization, needs, and concerns related to the resources)

- discussion of options and implications

Analysis steps are encapsulated below in Collaborative Review and Plan Initiation.

\section{Formulation}

- initial plan development (policy, process, and/or supporting documents)

- internal plan and document review and/or revisions

- external plan and document review (gather suggestions, questions, and concerns)

- final plan and document revisions

- develop communication, training, and implementation strategies

Formulation steps are encapsulated in Small Group Review and Structure Development and Large Group Collaborative Review and Shared Decision Making. 


\section{Implementation}

- layered communication

- plan and resource rollout

- future review and revisions (as needed)

Implementation steps are encapsulated in Statewide Rollout, Utilization and Reflection.

\section{Collaborative Review and Plan Initiation}

The practitioner group, composed of field-based faculty/staff and the state volunteer specialist, began the strategic management review in spring of 2017. This group was representative of 60 4-H faculty and staff from 24 local programs utilizing over 3,000 adult volunteers to serve approximately 8,000 club members and 50,000 youth through all delivery modes annually. The group was tasked with reviewing the 4-H volunteer system to create a platform for transitioning away from the short-term volunteer role to a more cohesive structure based on the needs of the different types of 4-H programs (club, in-school/after-school and outreach).

The group was specifically asked to review

- the types of volunteer roles and responsibilities needed and used by 4-H programs across the state,

- the volunteer onboarding process and procedural steps followed for different volunteer roles, and

- any liability issues encountered by volunteer managers from local offices.

The review began with a face-to-face work session of the practitioner group to discuss legal counsel's recommendations, county utilization, and the volunteers' needs from the field. The practitioner group reviewed the current volunteer documents and processes including the types of volunteer roles used by field faculty, screening and onboarding processes, liability issues, volunteer responsibilities, potential negative impact on volunteers, and rescreening/retraining needs. Through this initial review and discussion, the group identified some key concerns:

- The volunteer onboarding process was inconsistently applied. The onboarding process (application, screening, interviewing, orientation and paperwork) for certified volunteers had been utilized for years and provided an increased comfort level for parents of youth participants, enhanced the importance of responsibilities, and demonstrated a level of professionalism. The same level of rigor of onboarding was not 


\section{Evaluating a Statewide 4-H Volunteer Structure}

applied to short-term volunteers. Requirements for short-term volunteers were merely a form to sign, including basic contact information.

- There were perceptions from field faculty/staff that certified and short-term volunteers were equivalent in stature and provided the same personal liability protection. Some programs used the short-term volunteer form to reduce paperwork for "volunteers" and allowed them to take on care, custody, and control of youth on behalf of the 4-H Program without being screened.

- Varied use of the short-term volunteer form. Some programs used the short-term volunteer form as it was intended, others used it to reduce paperwork as stated above, and some did not use it at all.

At the conclusion of the initial review, a consensus was reached to develop a volunteer structure that would provide a clear understanding of volunteer roles within the 4-H Program including protections for individuals, volunteers, and the organization itself.

\section{Small Group Review and Structure Development}

A small group, comprised of the two chairs of the practitioner group and the state volunteer specialist, worked to develop a new volunteer structure addressing the concerns identified by the practitioner group. From May to October of 2017, this small group convened virtually to discuss, create, review, and revise a draft "product" that addressed the following needs of the system structure:

- having an accurate record of volunteers serving the 4-h program,

- consistently screening individuals to ensure the quality of the applicant,

- providing a level of liability protection for volunteers supporting 4-h work, and

- communicating clear expectations and/or requirements for each volunteer role.

The small group began by categorizing the different types of volunteer roles based on specific duties included in their volunteer position descriptions as well as their responsibility to take on the care, custody and control of youth on behalf of the 4-H Program. What emerged were three distinct types of volunteers, each with a different level of responsibility for youth safety:

- Volunteers with direct contact with youth and direct authority to take on the care, custody, and control for the 4-H Program. These were individuals who run clubs, programs, events, and activities for 4-H without a 4-H faculty/staff present. 


\section{Evaluating a Statewide 4-H Volunteer Structure}

- Volunteers with direct or indirect and supervised contact with youth. These were individuals that assisted with a club, program, event, or activity, but did so under the supervision of a 4-H faculty/staff member or a volunteer with direct authority.

- Individuals that helped and/or assisted at events that had indirect, limited or no contact with the youth and just wanted to help out the 4-H program.

Based on program needs and the three types of volunteers listed above, the draft "product" that was created was a tiered volunteer system chart that included the following volunteer types: certified volunteers, episodic volunteers, and event assistants. The chart, titled Tiered Volunteer System (Morris et al., 2017), clearly describes the term of service, renewal expectations, onboarding and paperwork requirements, leadership ability, and specific volunteer positions for each of these volunteer types.

In preparation for a statewide retreat in October 2017, an initial review of the chart by the program leader was facilitated by the volunteer specialist. Suggestions from this review led to the creation of two volunteer system options that would be presented to all 4-H faculty and staff. One option was the tiered volunteer system as written, which was re-named the threetiered volunteer system. The second option was a two-tiered volunteer system that included the two most critical roles of certified and episodic volunteers selected for the screening requirements which was an improvement from the previous short-term volunteer role.

\section{Large Group Collaborative Review and Shared Decision Making}

In October 2017, the practitioner group presented their work to colleagues at a statewide retreat for 4- $\mathrm{H}$ faculty and staff. The presentation included a review of what led to the need for change, the work the group had accomplished, and an overview of the options being presented for consideration. A chart of each system (two-tiered and three-tiered) were provided and reviewed in depth by small groups. Discussions were facilitated to help individuals digest and interpret the information. Each group was asked to provide written feedback regarding their thoughts, concerns, and potential utilization of each system in their respective local 4-H program.

After the retreat, the feedback collected was reviewed by the practitioner group, which indicated that the field was split between the two options: two-tiered and three-tiered volunteer systems. Clear concerns and needs emerged, which the small group was tasked with addressing 


\section{Evaluating a Statewide 4-H Volunteer Structure}

through revisions and the creation of supporting documents. A major revision to the proposed system was adding clarification to each type of volunteer that included role-specific information:

- length of service and renewal requirements,

- onboarding process requirements,

- positions they can assume, and

- expectations regarding their ability to take on the care, custody, and control of youth on behalf of the 4-H program.

In February of 2018, all feedback, group revisions, and supporting documents were delivered to the program leader for a final decision. Ultimately there was no support for an official event assistant role in the three-tiered system; therefore, a two-tiered system was established that included certified and episodic volunteers for the Maryland 4-H Program. Information regarding how to utilize non-volunteers was included in the final product that was reviewed and approved by legal counsel in March of 2018, titled Maryland 4-H Volunteer Roles. Supporting documents included an episodic volunteer application and an episodic volunteer appointment agreement.

\section{Statewide Rollout, Utilization, and Reflection}

The new two-tiered volunteer system was shared with Maryland 4-H faculty/staff in March 2018. Starting at a statewide face-to-face meeting of 4-H faculty and staff, the system, documents, and utilization were presented and followed up with a layering of information and support. The system was shared with faculty and staff during their monthly online state 4-H Connect sessions, and a recorded training webinar was conducted and shared as well. The rollout plan was intentionally designed to increase access to information and understanding of the system and processes. Each local program was expected to adhere to the expectations and requirements detailed in the Maryland 4-H Volunteer Roles, but was given the authority to utilize the roles as best fit their program needs.

\section{Discussion}

The Maryland 4-H Program has been using the Maryland 4-H Volunteer Roles since the spring of 2018; the state 4-H office monitors the usage through data from 4HOnline, conversations with field faculty and staff, and a volunteer management survey administered by the volunteer specialist. From informal conversations and observations, it is clear that 4-H faculty and staff across the state are understanding the expectations and applying the system to their programs. 


\section{Evaluating a Statewide 4-H Volunteer Structure}

Most have chosen to offer only the Certified Volunteer option, as it provides the best protection for everyone involved. Based on the volunteer data input into 4HOnline by local program volunteer managers, there seems to be a limited use of the episodic volunteer option. Staff have shared that the amount of onboarding and paperwork required for episodic volunteers outweigh their potential service to the program which is limited to serving a maximum of two months in a calendar year.

An intentional evaluation of the tiered volunteer system was conducted in the fall of 2019 by the volunteer specialist through a volunteer management program evaluation that included a targeted question on the use of episodic volunteers and direct conversation with 4- $\mathrm{H}$ faculty and staff during a statewide retreat. All confirmed abolishing the use of the short-term volunteer role and form and the consensus from the conversations showed an understanding of the increased protection provided through the episodic volunteer process-specifically, from the more rigorous risk management practices for episodic volunteers as compared to short-term volunteers. Episodic volunteers are required to be background checked and limited to specific roles and terms of service, unlike short term volunteers, who previously had no requirement to be screened or limits/specifics on service. In 2019 16\% of local programs reported using episodic volunteers and $13 \%$ responded that they may consider using this option if a need arises in the future. Some confusion in the utilization and requirements for episodic volunteers was reported by $13 \%$ of local programs, indicating a need for future work in communication and incorporation; this will be combined with additional evaluation of the system.

\section{Implications for Organizations}

To ensure the protection of clientele, volunteers, and employees, a consistent and cohesive volunteer system should be in place in the organization. This system should be based on a critical review of risks and rewards to the organization when using volunteers and should include clear processes and expectations. However, any system or structure is only as good as those that follow and implement it. Therefore, it is essential to train and provide support to those who engage volunteers and conduct regular reviews of the volunteer system to identify any gaps, voids or needs that may arise due to staff turnover, or societal or policy changes. A regular review might be less intensive than a strategic management review, but can follow a similar timeline and steps, and would benefit from including key employees.

A strategic review and use of a strategic management process similar to the one conducted by the UME 4-H should include the following: 


\section{Evaluating a Statewide 4-H Volunteer Structure}

- Analysis

- critical review of the program's needs, concerns and/or structure

○ support from upper-level leadership and/or administration

- Formulation

- creation and/or revision of documents supporting the specific area under review

o initial review by upper-level leadership and/or administration

- solicited input and feedback from individuals essential to program implementation and/or management

o revisions using feedback and final review by upper-level leadership and/or administration

- Implementation

- creation and initiation of an intentional rollout and communication plan

- layered communication, support, and training

- regular evaluation and revisions to meet the needs of the program and protect against risk

By participating in a collective and systematic manner, an organization can strengthen the program and support by honestly addressing issues before or as they arise. Working in a collaborative and comprehensive manner can increase an individual's buy-in to impending change and shorten transition time to a new process or system. Although change is often feared, it should be seen as a necessary and beneficial step towards the future when it comes to providing protection.

\section{Conclusion}

From 4-H's humble beginnings, volunteers have and will continue to play a crucial role in its success, as they also do in other youth development organizations. Just as a program or organization must continually evolve to meet the needs of the youth it serves, it must also evolve to meet the needs of the volunteers serving the program. This includes adequately protecting volunteers as well as the program, and constantly working to minimize potential risks. Conducting regular or strategic reviews of an organization's volunteer process is a riskmanagement strategy. By implementing this and other risk-management strategies for volunteerism, an organization can create a positive, safe, and inclusive environment for all. 
Journal of Youth Development | http://jyd.pitt.edu/ | Vol. 15 Issue 4 DOI 10.5195/jyd.2020.857 Evaluating a Statewide 4-H Volunteer Structure

\section{References}

Montanari, J. R., \& Bracker, J. S. (1986). The strategic management process at the public planning unit level. Strategic Management Journal, 73), 251-265. Wiley. https://www.jstor.org/stable/2486076

Morris, J., Ashby, L., \& Johnston, C. (2017). Tiered volunteer system from Maryland 4-H volunteer roles. University of Maryland.

Pleskac, S. (2010). ISOTURE Model of volunteer administration and development. National 4-H Council. https://4-h.org/wp-content/uploads/2016/02/ISOTURE-Model.pdf

Shmiesing, R. J., \& Henderson, J. (2001). Identification of volunteer screening practices for selected Ohio youth organizations. Journal of Extension, 39(1). https://www.joe.org/joe/2001february/a2.php

Seel, K. (Ed.). (2010). Volunteer administration: professional practice. LexisNexis, Canada.

Seevers, B., Graham, D., Gamon, J., \& Conklin, N. (1997). Education through Cooperative Extension. Delmar.

Tremper, C; Kostin, G. (1993). No surprises: Controlling risks in volunteer programs. Nonprofit Risk Management Center.

Vanhorn, B., Flanagan, C., \& Thomson, J. (1998). The first fifty years of the 4-H program. Journal of Extension, 36(6). https://www.joe.org/joe/1998december/comm2.php 